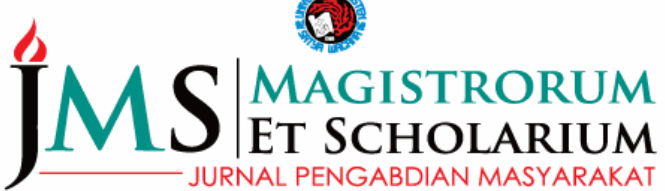

P-ISSN: 2722-9270 ejournal.uksw.edu/jms

\section{Komunikasi Sosial bagi Kepolisian melalui Media Video Instruksional}

Dewi Kartika Sari*

Sampoerno

Seto Herwandito

Budhi Widi Astuti

Ester Krisnawati

Pratiwi Cristin Harnita

Sih Natalia Sukmi

Bonardo Marulitua A.

Program Studi Ilmu Komunikasi, Universitas Kristen Satya Wacana

dewi.sari@uksw.edu

A R T I C L E I N F O

Article history:

Received 23-11-2020

Revised 23-11-2020

Accepted 14-12-2020

Key words:

Komunikasi sosial, video instruksional, kepolisian, masyarakat

\begin{abstract}
A B S T R A C T
Social communication in the police institution is important to develop community-oriented policing (COP). This social communication can be a communication bridge between the police and the community for the purpose of integration or social adaptation. For this purpose, community service is carried out at the Pusdik Binmas Lemdiklat Polri in the form of making instructional videos for Binmas functions in the community. Instructional videos are expected to provide an overview about the synergy between the police and the community. The method used in this service is carried out through pre-production, production and post-production activities. As a result of community service there are eight instructional videos for use at the Pusdik Binmas Lemdiklat Polri.
\end{abstract}

\begin{abstract}
A B S T R A K
Komunikasi sosial di lembaga kepolisian merupakan hal penting untuk mengembangkan community-oriented policing (COP). Komunikasi sosial ini dapat menjadi jembatan komunikasi antara kepolisian dengan masyarakat untuk tujuan integrasi atau adaptasi sosial. Untuk tujuan inilah maka dilakukan pengabdian masyarakat di Pusdik Binmas Lemdiklat Polri dalam bentuk pembuatan video instruksional fungsi Binmas di masyarakat. Diharapkan dengan adanya video instruksional ini, dapat memberikan gambaran kepada kepolisian tentang sinergitas antara
\end{abstract}

\footnotetext{
*Corresponding author: dewi.sari@uksw.edu
} 
kepolisian dan masyarakat. Metode yang digunakan dalam pengabdian ini dilakukan melalui kegiatan pra produksi, produksi dan pasca produksi. Hasil dari pengabdian masyarakat yakni terdapat delapan video instruksional untuk digunakan di Pusdik Binmas Lemdiklat Polri.

\section{PENDAHULUAN}

Gerakan reformasi lembaga kepolisian merupakan gerakan yang akhir-akhir ini tengah menjadi perbincangan di masyarakat. Konsep Community Oriented Policing (COP) atau dalam istilah Bahasa Indonesia disebut dengan Perpolisian Masyarakat (Polmas) merupakan konsep yang digunakan dalam aktivitas reformasi lembaga kepolisian tersebut (Meutia, 2016; Nuryana, 2003). Polmas merupakan strategi dari perpolisian yang melibatkan masyarakat dalam berbagai kegiatan kepolisian untuk tujuan keamanan masyarakat. Sehingga pelibatan masyarakat dalam kegiatan kepolisian disesuaikan dengan surat Keputusan Kapolri No. Pol.: Skep/737/X/2005, merupakan pendorong bagi lembaga kepolisian untuk berubah di dalam sikap, perilaku dan kultur dari "Military Policing" yang befehl ist befehl (perintah adalah perintah) menjadi "Civilian and Profesional Policing" yang berorientasi pada protect and with the people, shaking hands with the people (melindungi, mengayomi, melayani, menyalami dan merangkul masyarakat) melalui Program COP atau Perpolisian Masyarakat (Polmas). Progam COP atau Polmas terdiri dari dua komponen utama yaitu: pertama, menciptakan kemitraan bersama antara polisi dan masyarakat, dan yang kedua, pemecahan persoalan bersama antara polisi dan masyarakat dalam soalsoal keamanan dan ketertiban masyarakat (Kamtibmas) agar tercipat situasi yang aman dan nyaman demi kesejahteraan seluruh komponen masyarakat.

Oleh karena itu, pembinaan potensi masyarakat dan hubungan polisi dan masyarakat perlu diintensifkan melalui pengembangan metode Community Policining. Kami dari pihak akademisi melihat bahwa terdapat "jurang" antara polisi dan masyarakat. Untuk menjembatani perbedaan pemahaman tersebut, maka pengabdian masyarakat ini penting untuk dilakukan. Kegiatan ini dilakukan agar tercipta sinergi antara masyarakat dan kepolisian. Dengan menggunakan konsep komunikasi sosial, diharapkan perbedaan persepsi terkait dengan dengan peran dan fungsi antara kepolisian dan masyarakat dapat teratasi dengan baik. Konsep komunikasi sosial dan komunikasi pembangunan secara substansial tidak memiliki perbedaan. Pembahasan di dalam kedua konsep tersebut sama-sama berbicara tentang komunikasi dimana komunikasi memiliki peranan untuk menunjang pelaksanaan program pembangunan untuk tujuan menciptakan perubahan yang lebih baik dalam suatu sistem sosial di masyarakat (Riva'i, 2016). Komunikasi sosial adalah sebuah proses interaksi sebuah lembaga atau seseorang dengan proses penyampaian pesannya ditujukan untuk membangun integrasi atau adaptasi sosial (Vera \& Wihardi, 2012). Secara lebih khusus, komunikasi sosial yang dilakukan dalam pengabdian ini berupa pembuatan media guna menyampaikan pesan untuk membawa perubahan yang lebih baik, untuk membangun integrasi dan adaptasi sosial. Media yang dimaksud adalah video instruksional. Video instruksional berisi penjelasan fungsi kepolisian dalam kaitannya dengan COP atau Polmas. 
Pengabdian masyarakat ini dilakukan oleh Program Studi Ilmu Komunikasi, Fakultas Ilmu Sosial dan Ilmu Komunikasi (FISKOM), Universitas Kristen Satya Wacana (UKSW) bekerjasama dengan Pusat Pendidikan Pembinaan Masyarakat (Pusdik Binmas) di Lingkungan Lembaga Pendidikan (Lemdiklat) Republik Indonesia. Pusdik Binmas Lemdiklat Polri merupakan lembaga pendidikan bagi kepolisian tingkat nasional yang berada di bawah naungan Markas Berkas Kepolisian Republik Indonesia (Mabes Polri) di Jakarta. Adapun lokasi pengabdian masyarakat ini utamanya dilakukan di dua tempat, yakni di Salatiga dan di Kabupaten Semarang. Dalam pelaksanaan kegiatannya, lokasi pengabdian masyarakat dilakukan di tempattempat lain seperti di Kelurahan Kemiri, Kecamatan Sidorejo, Stasiun Tawang Semarang, BKPH Kedung Jati.

Kerjasama yang dilakukan antara Program Studi Ilmu Komunikasi UKSW dengan Pusdik Binmas Lemdiklat memiliki tujuan untuk membantu Pusdik Binmas Lemdiklat dalam pembutan video pembelajaran bagi calon-calon Polisi yang akan menjalani pendidikan di lembaga tersebut. Isi dari media pembelajaran yakni tentang komunikasi sosial antara kepolisian dengan masyarakat. Media tersebut diharapkan dapat memberikan gambaran secara praktis tentang peran dan fungsi seorang Polisi agar dapat berkomunikasi dengan baik ketika melayani dan memecahkan masalah yang dihadapi oleh masyarakat. Media ini juga dibuat agar calon-calon Polisi dapat memahami kondisi riil di masyarakat terkait dengan pelaksanaan tugas kepolisian yang nantinya akan diemban.

Terkait dengan manfaat pengabdian masyarakat, setidaknya ada dua manfaat yang diperoleh dengan pelaksanaan kegiatan ini. Manfaat pertama adalah manfaat teoritis. Integrasi pengabdian dan pendidikan dalam kegiatan ini adalah munculnya konsep komunikasi sosial dalam bentuk teoritik maupun dalam bentuk yang lebih aplikatif yakni berupa media video. Penggabungan kedua konsep ini dapat memberikan kontribusi bagi pengembangan keilmuan khususnya pengembangan Ilmu Komunikasi. Manfaat kedua yakni manfaat praktis. Manfaat praktis yang diperoleh diantara kedua lembaga pendidikan adalah terciptanya sinergitas antara Universitas Kristen Satya Wacana dan Pusdik Binmas Lemdikpol. Selain kerjasama antar lembaga pendidikan ini, diharapkan juga ada hubungan kerjasama yang baik dengan lembaga negara yaitu dengan Kepolisian Republik Indonesia (POLRI). Manfaat praktis kedua yakni terkait dengan kontinuitas kerjasama. Kerjasama tersebut diharapkan tidak hanya berhenti dalam satu kegiatan ini saja, akan tetapi dikemudian hari dapat dilakukan pengabdian masyarakat yang berkelanjutan atau bahkan kerjasamakerjasama dalam bentuk lain sesuai dengan kebutuhan masing-masing lembaga. Dengan demikian, Program Studi Ilmu Komunikasi UKSW dapat memberikan sumbangsih bagi lembaga pendidikan kepolisian dalam menghadapi permasalahan dalam lingkup sosial kemasyarakatan.

\section{METODE PELAKSANAAN}

Dalam menyelesaikan permasalahan yang muncul, metode pelaksanaan pengabdian masyakarat Prodi Ilmu Komunikasi UKSW dengan Pusdik Binmas Lemdiklat dilakukan dalam tiga tahapan. Ketiga tahapan tersebut dapat digambarkan 
sebagai berikut:

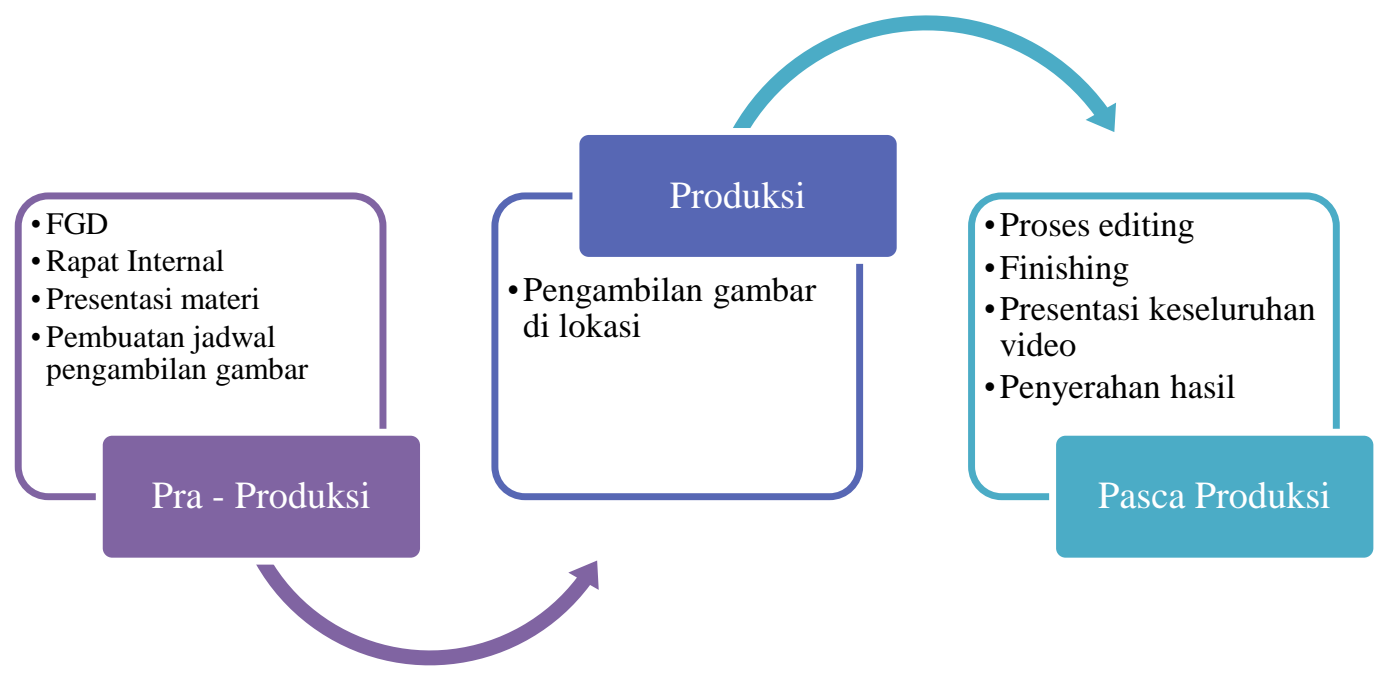

Gambar 1. Tahapan Pengabdian Masyarakat

Tahapan pembuatan video secara umum adalah pra produksi atau perencanaan, kemudian tahap produksi dan yang terakhir adalah tahap paska produksi (Honthaner, 2010). Pertama, tahap pra produksi terbagi menjadi beberapa bagian. Bagian pertama adalah melakukan Focus Group Discussion (FGD) antara Program Studi Ilmu Komunikasi dengan Pusdik Binmas Lemdikpol. Dalam kaitan ini, FGD dipilih karena dua alasan. Pertama, untuk mendapatkan gambaran pengalaman dari para tenaga pendidik di Pusdik Binmas Lemdikpol. Kedua, dengan dilaksanakannya FGD ini, terdapat ruang dialog yang akan saling mengkonfirmasi atau memperdebatkan sebuah gagasan atau ide diantara para peserta FGD, dengan demikian kekayaan data untuk pembuatan video instruksional akan diperoleh dengan baik (Irwanto, 2006). FDG ini dilakukan pada tanggal 2 Maret 2016 yang bertempat di Pusdik Binmas Lemdiklat Jl. Bhayangkara No. 1, Desa Kebondowo, Kecamatan Banyubiru, Kabupaten Semarang, Provinsi Jawa Tengah. FGD ini dilakukan dalam rangka mencari permasalahan yang dihadapi oleh Pusdik Binmas Lemdikpol. FGD juga dilakukan untuk menggali informasi-informasi terkait materi pembelajaran yang akan dibuatkan video instruksional. Selanjutnya, dilakukan bagian kedua yakni rapat internal Program Studi Ilmu Komunikasi. Rapat dilakukan pada tanggal 2 Maret 2016. Agenda rapat adalah mendiskusikan hasil pertemuan FGD dengan Pusdik Lemdikpol. Setelah itu, dilakukan bagian ketiga yakni presentasi materi video. Hasil presentasi tersebut adalah terdapat delapan rancangan media yang akan dibuat video instruksionalnya. Kemudian dari delapan materi tersebut masing-masing dikembangkan menjadi storyline dan storyboard. Storyline dan storyboard penting dalam proses pembuatan video karena keduanya dapat menjadi panduan atau pedoman kita dalam pengambilan gambar di lapangan. Kita dapat memiliki daftar gambar apa saja yang akan kita ambil di lapangan (Torta \& Minuty, 2018). Meskipun nanti di lapangan, pengambilan gambar dapat disesuaikan, namun pedoman storyline dan storyboard dapat membantu kita pada saat itu. Setelah storyline dan storyboard dibuat, langkah berikutnya adalah tim Dosen Prodi Ilmu Komunikasi membuat time schedule untuk proses produksi video 
instruksional.Tahapan kedua yang dilakukan setelah tahap pra produksi adalah tahap produksi. Tahap produksi adalah tahap tim pengabdian masyarakat melakukan pengambilan gambar di lokasi pengambilan gambar (lokasi shooting). Lokasi pengambilan gambar tersebut, diantaranya dilakukan di Kelurahan Kemiri, Kecamatan Sidorejo, Stasiun Tawang Semarang, BKPH Kedung Jati, dan di lingkungan kampus UKSW. Masing-masing tim akan bekerja berdasarkan pada storyline dan storyoard serta berdasarkan pada jadwal yang telah dibuat pada tahap pra produksi.

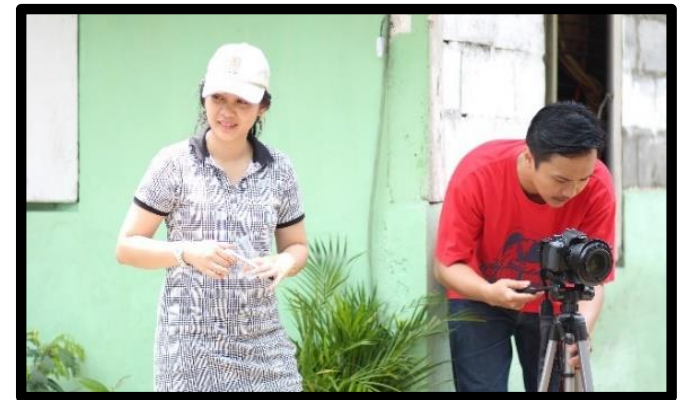

Gambar 1. Shooting di lokasi yang dilakukan salah satu tim pengabdian masyarakat

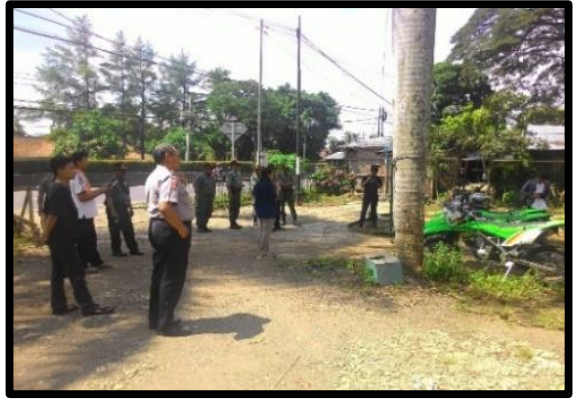

Gambar 2. Tim pengabdian masyarakat bersama Kepolisian shooting di lokasi

Proses produksi pengambilan gambar tidak hanya dilakukan di luar ruangan saja, tetapi juga dilakukan di Laboratorium Terpadu Fakultas Ilmu Sosial dan Ilmu Komunikasi (FISKOM). Proses produksi yang dilakukan di Laboratorium Terpadu adalah proses pengambilan gambar presenter atau host untuk video instrusional tersebut dan juga produksi audio untuk mengisi narasi pada video. Proses pengambilan gambar dilakukan di laboratorium televisi, sementara proses produksi audio dilakukan di laboratorium radio.

Tahapan ketiga setelah pra produksi, kemudian tahap produksi yakni proses editing dan finishing dari video yang telah dibuat. Proses editing adalah proses dimana gambar-gambar video dan narasi audio yang telah direkam, kemudian dibuat menjadi serangkaian cerita disesuaikan dengan storyline dan storyboard yang telah dibuat sebelumnya. Editor tersebut memilih atau menyunting video dan audio tersebut dengan menggunakan software Adobe Premiere dan Adobe Illustrator. Edit video dilakukan di laboratorium komputer FISKOM. Pada saat editing, tidak lupa dicantumkan logo dari FISKOM dan dari Pusdik Binmas Lemdiklat Polri. Tahap terakhir dari pengabdian masyarakat adalah penyerahan hasil delapan video instruksional kepada pihak Pusdik Binmas Lemdiklat Polri.

\section{HASIL DAN PEMBAHASAN}

Hasil pengabdian masyarakat Prodi Ilmu Komunikasi ini berupa pembuatan delapan video instruksional bagi kepolisian. Pembuatan delapan video instruksional ini didasarkan pada dua kali FDG yang dilakukan oleh Prodi Ilmu Komunikasi UKSW dengan Pusdik Binmas Lemdiklat Polri. Berdasarkan hasil FGD tersebut, maka tim Dosen Prodi Ilmu Komunikasi membuat rancangan media berupa video instruksional. Berikut ini adalah delapan materi yang telah dibuat : 
1) Video tentang Bimbingan Ketertiban dan Keamaman Masyarakat (Bintibmas).

2) Video tentang Materi Konsepsi Pembinaan Keamanan Swakarsa Dan BentukBentuk Pengamanan Swakarsa.

3) Video tentang Manajemen Binkamsa.

4) Video tentang Pengamanan Tempat Kejadian Perkara (TKP) oleh Satpam.

5) Video tentang Kepolisian Khusus (Polsus).

6) Video tentang Konsepsi Pembinaan Polisi Masyarakat (Binpolmas).

7) Video tentang Door To Door System.

8) Video tentang Kasus Tindak Pidana Ringan (Tipiring).

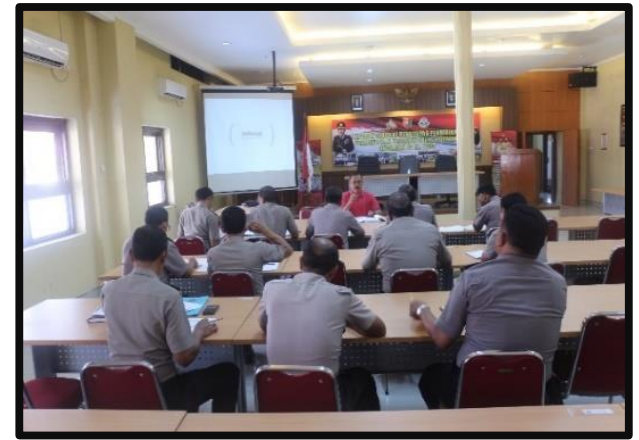

Gambar 3. Focus Group Discussion (FGD)

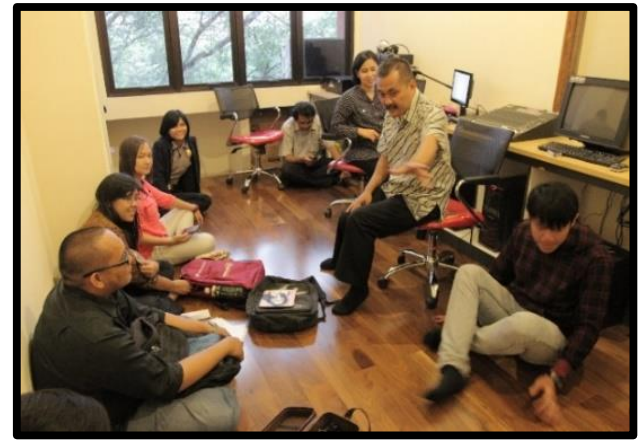

Gambar 4. Rapat Internal Tim Dosen

Delapan judul video instruksional yang telah dibuat, merupakan hasil FGD dengan para tenaga pendidik (gadik) di Pusdik Binmas Lemdiklat Polri. Para gadik di Pusdik Binmas Lemdiklat tersebut dibagi menjadi delapan kelompok kecil. Hasil diskusi tersebut diperoleh informasi bahwa bentuk pembelajaran selama ini yang terjadi di Pusdik Binmas Lemdiklat Polri adalah bentuk pembelajaran berupa penjelasan materi dari power point. Para gadik mengharapkan agar pembelajaran tersebut dapat ditunjang dengan video.

Pemilihan media video diperlukan karena belum ada materi berupa video. Selain itu, video yang digunakan dalam pembelajaran merupakan salah satu pendekatan agar pembelajaran menarik untuk siswa yang sedang belajar. Melalui video ini, berbagai macam bentuk pengetahuan dapat ditampilkan dengan cara-cara kreatif, sehingga selain video dapat menarik perhatian dari siswa, dapat juga memberikan penjelasan yang melengkapi mengenai sebuah konsep dari sebuah teks.

Kelebihan dari kegiatan pengabdian ini adalah tersedianya video pembelajaran di lingkungan Pusdik Binmas Lemdiklat Polri setelah sebelumnya belum ada video pembelajaran ini. Video instruksional ini memberi manfaat baik bagi tenaga pendidik, maupun bagi siswa. Manfaat bagi gadik adalah memberikan kemudahan dalam hal penyampaian materi. Materi yang sebelumnya dijelaskan dengan teks powerpoint, dapat dijelaskan melalui gambar visual dan audio, sehingga materi teks dari gadik dapat dipahami dengan lebih baik oleh siswa. Manfaat lainnya adalah ada saatnya gadik perlu menjelaskan lingkungan atau situasi di masyarakat. Sebelumnya, penjelasan ini berupa kata-kata yang disampaikan oleh gadik. Gambaran atau imajinasi siswa bisa saja berbeda dengan gambaran dari gadik. Dengan adanya video instruksional ini, gambaran situasi yang ada di masyarakat menurut imajinasi gadik, dapat diterima dengan mudah oleh siswa. Siswa dapat melihat video instruksional dan 
dapat memahami dengan mudah untuk setiap situasi atau kasus yang ada di masyarakat. Disisi lain, video instruksional ini juga dapat bermanfaat bagi siswa. Video ini berisi gambar atau visual dan audio serta teks yang dikemas secara bersamasama untuk tujuan pemahaman bagi siswa. Aspek lengkap dari video ini dapat juga memberikan pemahaman lebih mendalam bagi siswa, karena semua unsur visual, audio, dan teks dapat dilihat dan didengar oleh siswa. Dengan demikian, pemahaman siswa terhadap materi tertentu dapat semakin meningkat. Penggunaan video instruksional juga dapat meningkatkan motivasi siswa dalam belajar. Video ini dapat menumbuhkan sikap dan menyentuh sisi afektif siswa.

Video instruksional selain memiliki kelebihan, penggunaan video ini juga memiliki kelemahan. Yang pertama, kekurangannya adalah proses komunikasi video ini bersifat satu arah. Sehingga pemutran video harus diimbangi dengan penggunaan umpan balik atau feedback lain, misalnya tetap diberi penjelasan atau gadik dapat menyampaikan pertanyaan terkait isi video kepada siswa. Kedua, video instruksional ini kurang menampilkan secara sempurna mengenai objek yang hendak dijelaskan. Sehingga perlu pendekatan lain agar pemahaman siswa tersebut dapat lebih lengkap. Kelemahan ketiga, penggunaan video ini perlu disesuaikan dengan waktu dan jaman. Contoh-contoh kasus yang ada di dalam video perlu diperbaharui sesuai dengan perkembangan jaman. Dengan demikian dibutuhkan kembali pembuatan video instruksional agar sesuai dengan perkembangan masa.

\section{SIMPULAN}

Kegiatan pengabdian masyarakat berupa pembuatan video instruksional untuk Kepolisian telah selesai. Pembuatan video yang dilakukan oleh Tim Dosen Program Studi Ilmu Komunikasi memberikan implikasi signifikan bagi Pusdik Binmas. Beberapa implikasi tersebut diantaranya, pertama, video instruksional ini memberikan pilihan metode pembelajaran bagi gadik di lingkungan Pusdik Binmas Lemdiklat Polri. Para gadik memiliki beragam metode pembelajaran selain ceramah. Dengan adanya video ini, membatu gadik untuk menyampaikan materi dengan kreatif. Disisi lain, implikasi bagi calon anggota Polisi yang melakukan pendidikan di Pusdik Binmas adalah memberi gambaran nyata kepada peserta didik tentang komunikasi sosial Kepolisian kepada masyarakat. Para peserta didik tidak hanya dapat membayangkan situasi yang terjadi di masyarakat, namun dapat melihat secara langsung gambaran situasi tersebut melalui tayangan video instruksional. Selain itu, dengan adanya variasi metode pembelajaran dengan menggunakan video, membuat peserta didik semakin mudah memahami pada materi yang diajarkan.

Dampak pengabdian masyarakat pada level kelembagaan, yakni institusi Kepolisian Republik Indonesia (Polri) juga dirasakan. Pusdik Binmas Lemdiklat Polri mengirimkan kedelapan video ini ke Markas Besar Kepolisin Republik Indonesia (Mabes Polri) di Jakarta. Menurut Kapusdik Binmas, Mabes Polri memberikan apresiasi yang sangat baik kepada Pusdik Binmas karena sudah membuat video instruksional ini dengan baik untuk menunjang pembelajaran di Pusdik Binmas.

\section{DAFTAR PUSTAKA}

Honthaner, E. L. (2010). The complete film production handbook (4th ed.). Elsevier Inc. 
Irwanto. (2006). Focused group discussion (FGD): Sebuah pengantar praktis. Yayasan Obor Indonesia.

Meutia, I. F. (2016). The implementation of community policing in Indonesia. Kanazawa University.

Nuryana, M. (2003). Membangun community policing melalui kemitraan polisikomunitas (Suatu model peningkatan ketahanan sosial di Indonesia). Sosio Informa, 8(3), 1-13. https://doi.org/https://doi.org/10.33007/inf.v8i3.1003

Riva'i, A. K. (2016). Komunikasi sosial pembangunan: Tinjauan teori komunikasi dalam pembangunan sosial. Hawa dan AHWA.

Torta, S., \& Minuty, V. (2018). Storyboarding: Turning script to motion (2nd ed.). Mercury Learning and Information.

Vera, N., \& Wihardi, D. (2012). "Jagongan" sebagai bentuk komunikasi sosial pada masyarakat Solo dan manfaatnya bagi pembangunan daerah. Jurnal Makna, 2(2), 58-64. https://doi.org/http://dx.doi.org/10.30659/jikm.2.2.40-46 


\section{LAMPIRAN}

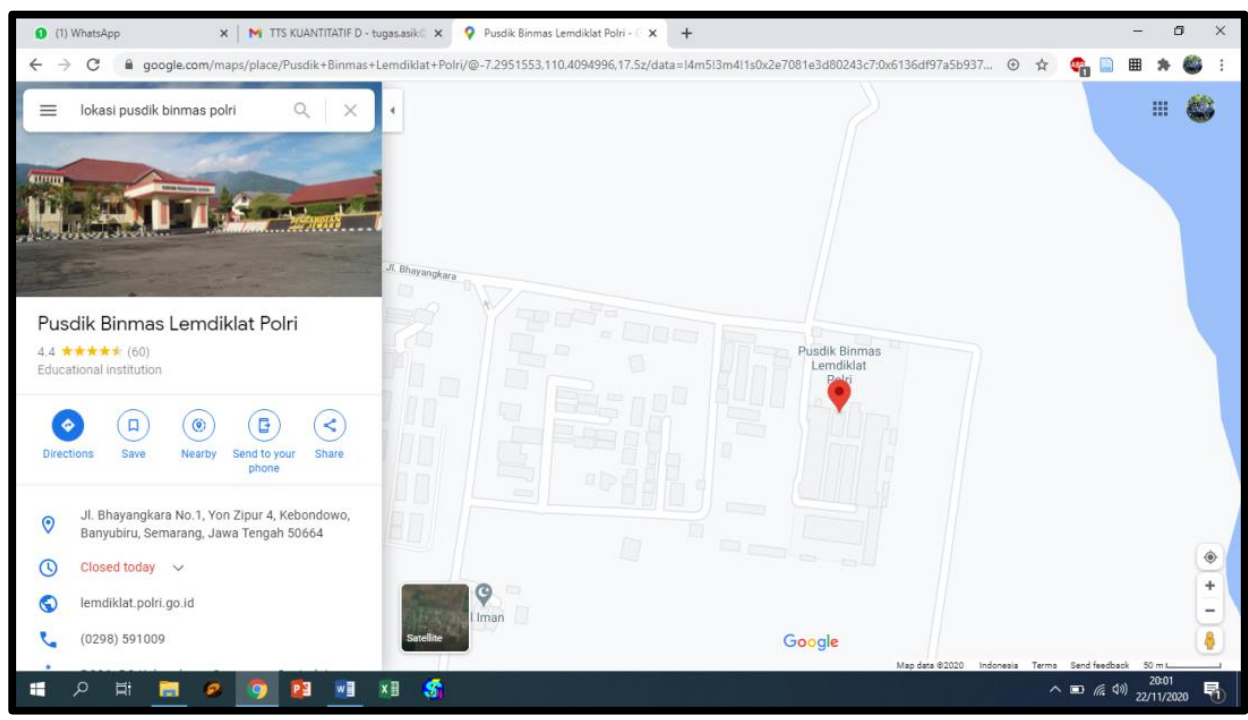

Lokasi Pusdik Binmas Lemdiklat Polri

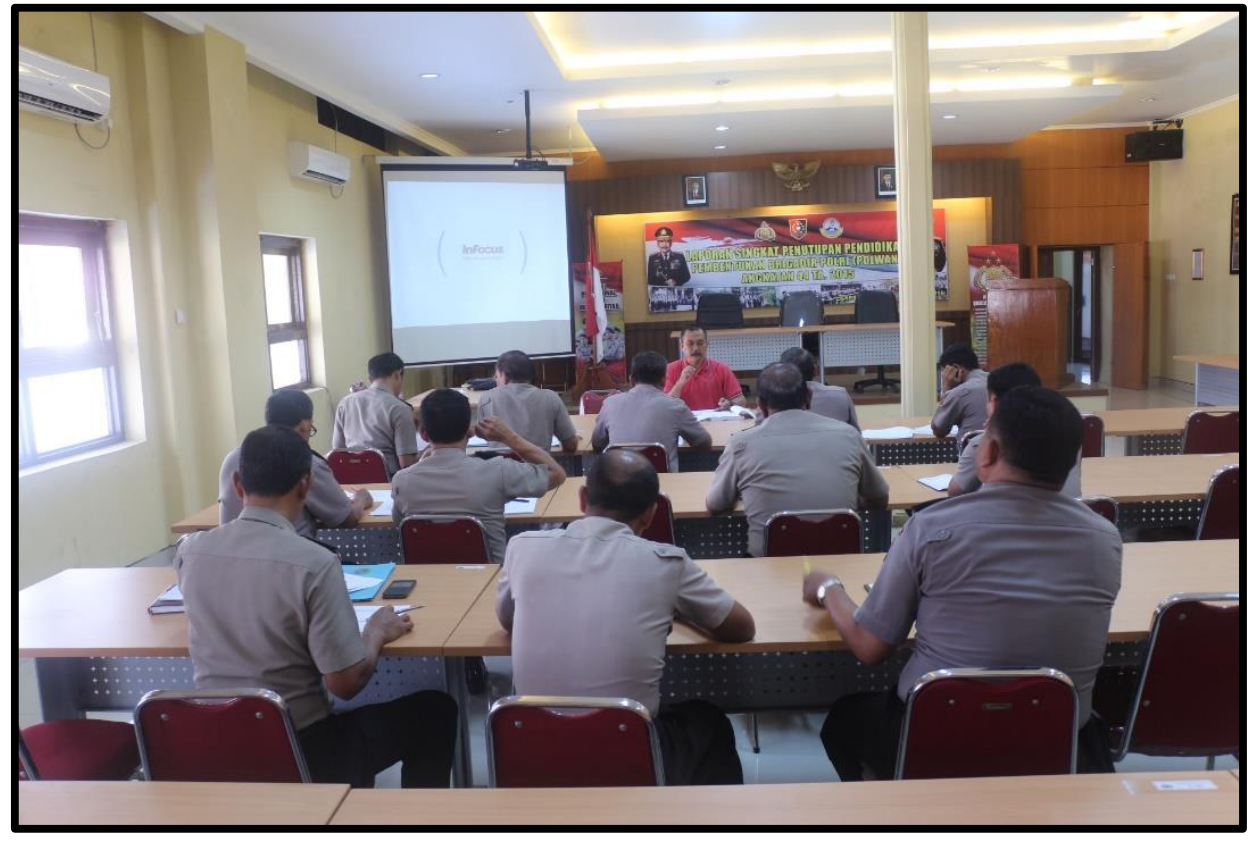

FGD di Pusdik Binmas Lemdiklat Polri 


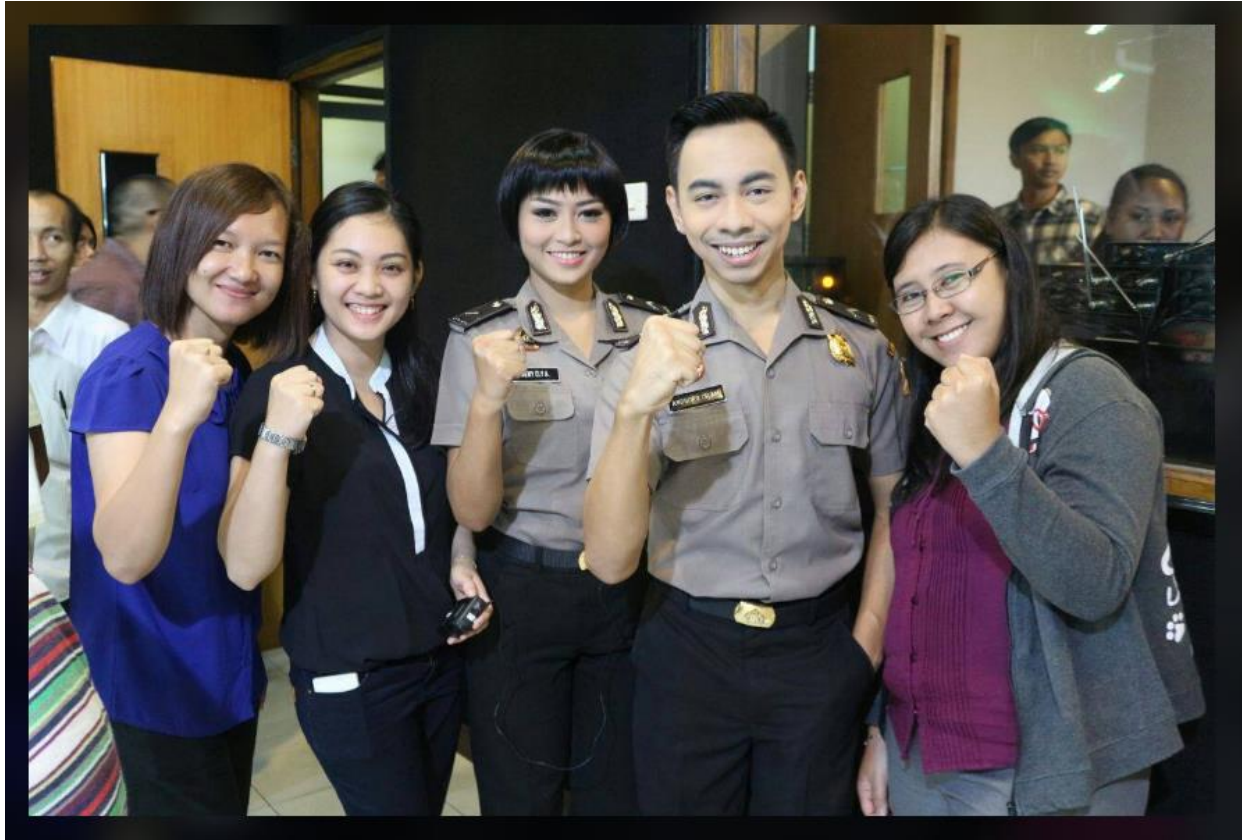

Produksi Video Instruksional di Laboratorium Televisi FISKOM 